\title{
Fungi at the Scene of the Crime: Innocent Bystanders or Accomplices in Oral Infections?
}

\author{
Christopher Delaney ${ }^{1} \cdot$ Ryan Kean $^{1,2} \cdot$ Bryn Short $^{1} \cdot$ Maria Tumelty $^{1} \cdot$ William McLean ${ }^{1} \cdot$ Christopher J. Nile $^{1}$. \\ Gordon Ramage ${ }^{1}$
}

Published online: 30 June 2018

(C) The Author(s) 2018

\begin{abstract}
Purpose of Review Over the last decade, microbiome studies have enhanced our knowledge and understanding of the polymicrobial nature of oral infections. Recently, profiling of the fungal microbiome has expanded our conventional understanding of oral ecology, revealing the critical importance of yeasts within this complex microbiome. This review aims to explore our current appreciation of interkingdom interactions in oral disease.

Recent Findings There is a growing evidence base of interactions and pathogenic synergy and antagonism with bacterial species within oral disease. Recent studies have helped to develop our knowledge of how Candida albicans, alongside bacteria such as Porphyromonas gingivalis, Streptococcus mutans, Staphylococcus aureus, Enterococcus faecalis, and Lactobacillus species, influence overall pathogenicity.

Summary Clinical and experimental evidence makes a compelling case for a role for C. albicans in a number of oral infections, though whether its role is an active accomplice or passive bystander remains to be determined.
\end{abstract}

Keywords Candida $\cdot$ Biofilm $\cdot$ Oral cavity $\cdot$ Polymicrobial $\cdot$ Interkingdom

\section{Introduction}

The oral ecosystem is a critical element in oral health, with dysbiosis perceived as the primary driver of disease phenotypes [1]. Recent studies have shown that ecobiological heterogeneity of the salivary ecosystem, its functionality, and its interaction with host-related biochemical salivary parameters are also important considerations in understanding disease processes in the oral cavity $[2 \bullet \bullet]$. However, a notable omission

This article is part of the Topical Collection on Mycology from all these studies is the importance of pathogenic fungi expressed in terms of the mycobiome, and how these eukaryotes impact the progression of various oral diseases. Indeed, fungi are often neglected in oral microbiology due to their relative low quantitative contribution within diseased sites of the oral cavity. Nevertheless, consideration of their size may lead to a rethink, as conservative estimates for a yeast cell biovolume is approximately $70 \mu \mathrm{m}^{3}$, whereas a bacterium is $0.5 \mu^{3}$ [3]. This almost 150-fold difference in the occupancy

William McLean

William.McLean@glasgow.ac.uk

Christopher J. Nile

Christopher.Nile@glasgow.ac.uk

1 Oral Sciences Research Group, Glasgow Dental School, School of Medicine, Dentistry and Nursing, College of Medical, Veterinary and Life Sciences, University of Glasgow, 378 Sauchiehall Street, Glasgow G2 3JZ, UK

2 Institute of Healthcare Policy and Practice, School of Health, Nursing, and Midwifery, University of the West of Scotland, Paisley, UK 
of available space upon orally relevant surfaces for fungi suggests that it is at least a bystander, but whether innocent or not remains to be determined.

The oral cavity contains numerous different micro-environments, ranging from enamel, mucosa, periodontal pockets, acrylic and metal substrates, and dentine, that are inhabited by tens to hundreds of bacterial species [4]. Polymicrobial communities are able to form biofilms upon this vast variety of substrates [5••, 6, 7]. It is now generally well understood that dental plaque biofilms contain many resident species that modulate one another, their environment, and also the host response [8-10]. Despite the widely acknowledged presence of yeasts within the oral cavity, their active role and participation in oral diseases is generally perceived to be restricted to mucosal-related diseases. Yet, in excess of 100 fungal species have been reported to colonise the oral cavity and co-exist within complex biofilm populations within aggregates alongside resident bacterial microbiomes [11]. The emergence of these datasets has been the catalyst for a number of studies investigating the importance of fungi within oral biofilm infections. This has fuelled the concept of interkingdom communities, which continues to grow above and beyond our traditional viewpoint of bacterial-bacterial interactions [12-14]. Indeed, the advancement in sequencing technologies has facilitated the characterisation of the fungal oral microbiome $[11,15 \bullet, 16]$. Within this review, the current evidence regarding fungal-bacterial interactions in the oral cavity and their clinical relevance will be evaluated, which are illustrated in Fig. 1.

\section{Identifying the Usual Suspects and Beyond}

The oral cavity contains one of the most diverse microbiomes of the human body, second only to that of the gastrointestinal tract [17]. The oral microbiome plays host to hundreds of eukaryotic and prokaryotic species. It is estimated that more than 600 species of bacteria [18] and 100 fungal species [16] can inhabit this "biome." Sequencing of "hypervariable" regions, such as the 16S rRNA (v1-9), for identifying genera of bacteria within communities has become commonplace within oral microbiology $[19,20]$. Within recent years, there has been a number of studies concerned with the compositional makeup of the oral microbiome, which varies dramatically between health and various diseases, as well as distinct ecological niches $[4,21,22 \bullet]$. The heterogeneity and diversity between niches observed within the oral microbiome is in part due to the numerous surfaces that exist within the oral cavity [4]. Microbiome studies in oral disease have demonstrated the existence of distinct microbial communities compared to health. In periodontitis microbiome studies, in contrast to other clinical host sites (e.g. gastrointestinal tract), an increased bacterial diversity and richness in disease has been reported compared to health $[23,24]$. Additionally, these studies have elucidated previously unappreciated species. Next-generation sequencing (NGS) technologies have revealed a greater complexity within the periodontal disease microbiome, well beyond the traditional "red complex" that is comprised of Tannerella forsythia, Porphyromonas gingivalis, and Treponema denticola [25]. Microbiome studies have shifted this dogma, showing the prevalence of many diseaseassociated genera and species, including but not limited to Spirochetes, Filifactor, and Fusobacterium, highlighting a more diverse disease community than previously considered $[19,26]$.

In contrast, limited oral fungal microbiome, or "mycobiome," studies have been published and disseminated, despite their increased recognition as an important pathogen in oral disease. As recently as 2010, a study led the way in characterising the fungal component of the oral microbiota via amplification of the internal transcribed spacer (ITS). Unlike $16 \mathrm{~S}$ sequences with fixed length amplicons, ITS sequences can produce variable sequence lengths, which make bioinformatic processing more challenging. The authors observed that the most common genera of fungi were Cladosporium, Aureobasidium, and Saccharomycetales [16], many of which were subsequently confirmed by Dupuy and colleagues [27]. Interestingly, amongst the observed operational taxonomic units (OTUs) were a number of genera that were not in consensus with the initial study, including Saccharomyces and a number of components, including the Saccharomycetales order that were not found in as high frequency as reported initially [16].

In more recent studies, comparisons between oral health and disease have been made. For instance, a study comparing the mycobiome of periodontal disease and healthy individuals reported similar levels of fungal species (over 100) compared to the first report [16]. However, in their cohort, it was observed that Candida and Aspergillus were the most frequent genera, being present in $100 \%$ of samples. Interestingly, there was no significant difference in the overall diversity of fungal taxa between periodontal disease and the healthy cohort, or the overall composition. An increase in abundance the Candida genus in periodontal disease compared to health was observed, although this was not found to be statistically significant [11]. Notably, this was a pilot study and was perhaps hampered by its limited cohort size. Future mycobiome studies with larger cohorts and more stringent classification of disease state and other metadata would provide a more comprehensive interpretation of the mycobiome in oral health.

With 16S now being well established, and ITS amplicon sequencing becoming more readily available, there is now the ability to perform co-occurrence studies [12, 15•]. Dual bacterium and mycobiome analysis of sites within oral cavity (endodontic) infections has been demonstrated by Persoon and colleagues (2017). This group demonstrated a cooccurrence of acidogenic bacteria in the presence of fungal 


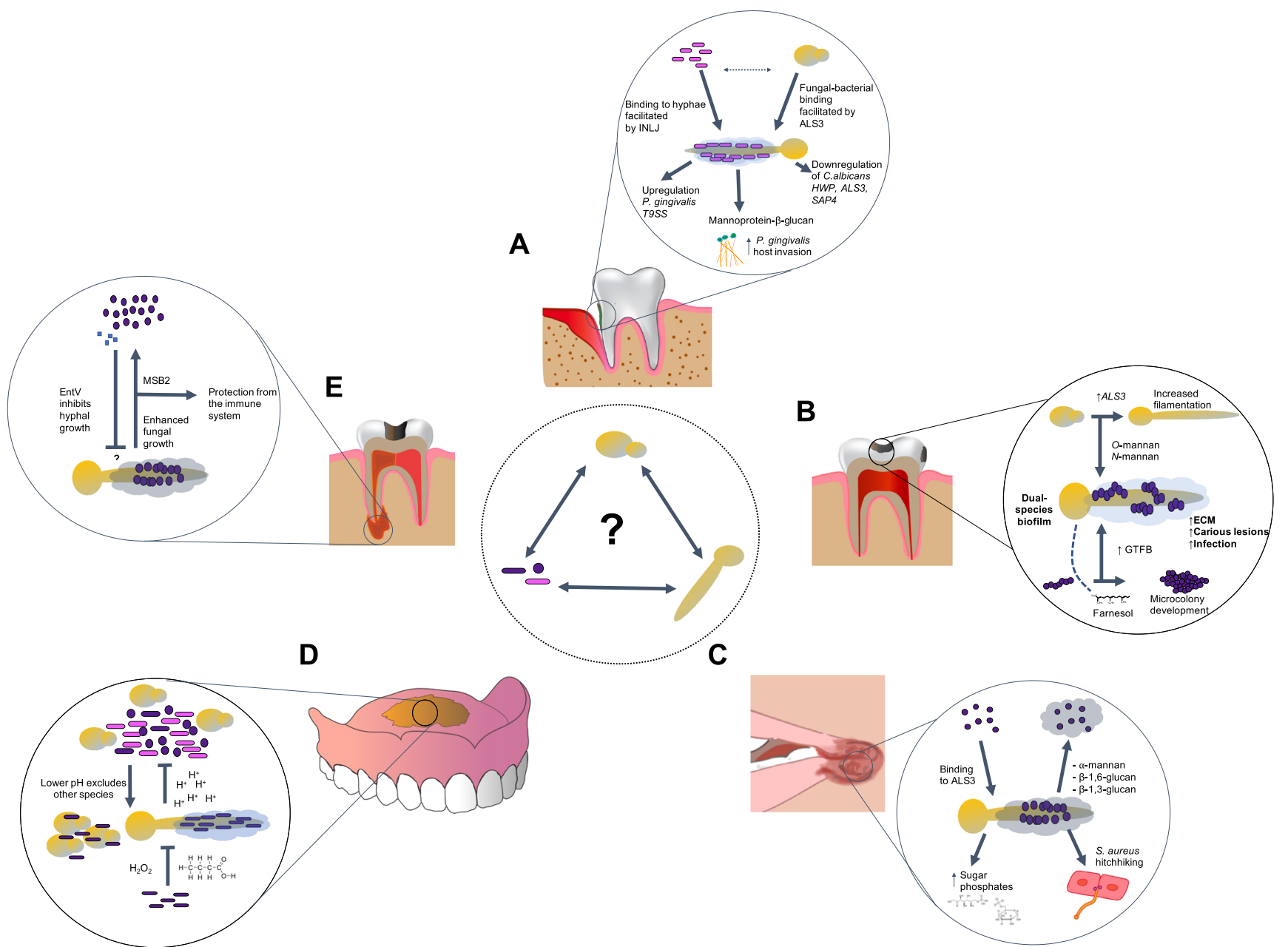

Fig. 1 Bi-directional interactions between fungal and bacterial species in oral infections. The diagram illustrates the sites of polymicrobial infection. a Periodontal pockets. b Caries. c Angular cheilitis. d

species, and an overall positive correlation of $C$. albicans with bacterial species. Negative correlations of bacterial species were observed with increased $C$. dubliniensis. These authors highlight the current limitations of these approaches, including increased difficulty in DNA extraction, PCR amplification due to length variation of ITS, and inconsistent fungal nomenclature. Despite these issues, as these types of studies grow and analytical pipelines become more developed, then the possibilities for understanding complex interkingdom interactions will become more fully realised.

\section{Periodontal Disease: An Uncontrolled Gangland}

Periodontal disease is a disease or group of diseases characterised by a complex host inflammatory response that is stimulated by microbial interactions from complex polymicrobial biofilm plaque. This subsequently leads to damage to the surrounding gingival tissues and supporting structures of the tooth. It varies in severity from reversible gingivitis to severe irreversible periodontitis, where the
Denture stomatitis. e Endodontic infection. At each of these sites, differing levels of fungal biofilm formation, hyphal switching and interactions occur as well as interactions with bacterial oral pathogens

periodontal ligaments and alveolar bone are destroyed [28]. Despite our ability to easily prevent this disease with oral hygiene measures, it remains one of the most prevalent diseases in the world, with nearly half of adults in the USA developing periodontitis [29]. Periodontal disease has a well-understood bacterial aetiology, with $P$. gingivalis considered the keystone pathogen within periodontitis [30] (Fig. 1a). Several other bacteria have also been implicated, including but not limited to Tannerella forsythia, Aggregatibacter actinomycetemcomitans, and Fusobacterium nucleatum [31, 32]. Given the diversity and numbers of other bacteria in and around the periodontal neighbourhood, then it is difficult to say with absolute certainty that particular periodontal pathogens are the sole cause of periodontitis. Indeed, the concept of oral ecotypes and pathotypes suggests that the sum of different varieties of periodontal pathogens and their functional capacity within the periodontal environment, despite functionally redundant metabolic processes, are more likely to drive synergised virulence leading to clinical disease $[2 \bullet \bullet]$. 
Several fungal species have been isolated from the periodontal pockets of patients with periodontitis, with Candida albicans generally being the most prevalent [33, 34]. Notably, the presence of $C$. albicans has also correlated with the severity of periodontitis [33]. Whether it is simply innocently colonising this environment and playing no active pathogenic role is unknown, yet mounting evidence suggests that it has the capacity to interact with periodontal pathogens and influence their behaviours. Specific bacteria frequently co-isolated with $C$. albicans in periodontal pockets include the anaerobes $F$. nucleatum and $P$. gingivalis. Remarkably, it has been shown that fungi are able to rapidly deplete oxygen within mixed species environments, which may explain why obligate anaerobes and yeasts are observed together [35]. For instance, $P$. gingivalis modulates and enhances the germ tube formation of C. albicans [36], whereas $F$. nucleatum has been demonstrated to inhibit $C$. albicans hyphal morphogenesis [37]. Other $P$. gingivalis-related studies however noted an antagonistic effect on the yeast-hyphal transition in C. albicans, with $P$. gingivalis notably downregulating hyphal related genes $A L S 3, H W P 1$, and SAP4 [38, 39]. Most recently, it has been demonstrated that the attachment of $P$. gingivalis to $C$. albicans is facilitated by the virulence factor InlJ from the internalin protein family, which interacts with the $C$. albicans adhesin ALS3 [40]. Additionally, co-adhesion specific interactions were observed, where adhesive interactions between these pathogens appear to induce the type 9 secretion system of $P$. gingivalis, a system characterised as having an increased community pathogenicity [41].

Further studies have shown that enhanced invasion of a gingival epithelial cell line and gingival fibroblasts by $P$. gingivalis is enhanced by pre-incubation with heat-killed cells and the mannoprotein- $\beta$-glucan complex from $C$. albicans [42]. The mechanism by which $C$. albicans facilitates this invasion is unclear, though the authors hypothesise that the recruitment of $C$. albicans cell wall components increases the recruitment of clathrin in epithelial cells. This is a mechanism by which $P$. gingivalis has been shown to invade host cells [14]. Further physical interactions have been investigated with F. nucleatum. This contact-dependent interaction is mediated by the FLO9 $C$. albicans cell wall protein and the $\operatorname{RadD} F$. nucleatum membrane protein, which prohibits the morphological switching from yeast to hyphae [37]. Only recently has this interaction of FLO9 and RadD have been shown to be necessary for co-aggregation of F. nucleatum and C. albicans under both planktonic and biofilm conditions [43]. It has additionally been shown that this co-aggregation with $F$. nucleatum has a modulatory effect on the innate immune response. MCP- 1 and TNF- $\alpha$ production are reduced during coaggregation, which Bor et al. (2016) conclude has the potential to provide a mutualistic protection from macrophage killing and recruitment of monocytes resulting in an increased persistence [37].
Finally, A. actinomycetemcomitans has been associated with severe periodontitis [44]. In vitro, A. actinomycetemcomitans adheres to hyphae, although interactions with $C$. albicans show decreased fungal biofilm formation which is mediated by the luxS-synthesised autoinducer-2 (AI-2)-dependent mechanism. This was also mirrored using the 4,5-dihydroxy-2,3pentanedione (DPD) synthetic molecule [45]. In Streptococcus gordonii, a ubiquitous oral commensal, it was shown that $C$. albicans hyphal formation was induced in a luxS-dependent manner, and that the addition of DPD had no effect on hyphal formation [13]. It is evident, as the authors concede, that more studies are necessary to elucidate the interactions between $C$. albicans and A. actinomycetemcomitans.

There is still many unknowns and conflicting evidence within the literature with regard to the importance of interkingdom relationships and their involvement in the progression of periodontitis. The literature does highlight some potentially important synergised pathogenicities of both the fungal and bacterial species, though further clinical studies are required to demonstrate functional dependency, perhaps starting with showing active presence of hyphae within periodontal pockets of patients with active disease.

\section{Caries: Slimy Residents}

Impacting 2.43 billion people globally, dental caries is the second most prevalent disease of humans, exceeded only by the common cold $[46,47]$. Dental plaque biofilms are responsible for this cause of tooth decay, predominantly through the biofilms ability to ferment dietary sugars such as sucrose into the production of intolerable quantities of lactic acid that ultimately results in the demineralisation of the tooth surface. If left untreated, the dissolution of the enamel and dentine within the tooth results in the formation of a cavity within the tooth, providing an ideal niche for the cariogenic biofilm to thrive and proliferate to progress disease [48]. Moreover, a consequence of sugar metabolism is the production of soluble and insoluble glucan "slime" that protects and encases the acidogenic microbiome.

Historically, Streptococcus mutans has been regarded as the primary etiological agent of this disease; however, recent microbiome studies of dental plaque have highlighted that caries may indeed be polymicrobial in nature [49, 50] (Fig. 1b). An organism of interest in this context is C. albicans, a yeast frequently isolated from patients with caries. Studies have identified a higher incidence rate of $C$. albicans in children with caries compared to caries-free children [51, 52]. A recent systematic review by Xiao and co-workers (2018) indeed confirmed this co-isolation, stating that children with oral $C$. albicans colonisation, can be $>5$ times more likely to develop early childhood caries (ECC) [53•]. The role for C. albicans colonisation as a risk factor for ECC should not be under-estimated and warrants further investigation. 
Collectively, do these findings suggest incorporating antifungal therapy in the treatment of ECC? [54].

Mechanistically, there have been several interesting observations, with both physical and chemically mediated signals facilitating these interactions. Perhaps the most welldocumented candidal adhesin with regard to interkingdom interactions is $A L S 3$. Genetic manipulation of this adhesin has been shown to reduce bacterial binding to hyphal filaments of $C$. albicans, reducing the invasive capacity of this relationship [55]. The role of this phenotype has been shown in several bacterial pathogens including Staphylococcus aureus, Streptococcus gordonii, and Streptococcus agalactiae [56-58]. Interestingly, when the $\Delta$ als3 strain was grown with $S$. mutans, no reduction was observed in mixed species biofilm formation, suggestive of a different mechanism of interaction [59]. However, it has been shown that the presence of $S$. mutans in a mixed species biofilm can induce transcriptional expression of this key adhesin [60]. Instead of a protein-based interaction, Hwang and colleagues (2017) demonstrated a mannan-mediated binding, whereby the extracellular $\alpha$ glucans of $S$. mutans interacted with a high affinity to the mannans of the $C$. albicans cell wall. Furthermore, they identified that mixed species biofilms formed with $C$. albicans strains defective in the outer mannan chain were unable to establish in vivo [59]. The exoenzyme glucosyltransferases (Gtfs) are predominantly responsible for the production of $\alpha$-glucans from dietary sugar, and it is known that these extracellular polysaccharides are the key mediators of these dual-species cariogenic biofilms. In the absence of sucrose, C. albicans demonstrates a weak co-aggregation with $S$. mutans; however, secreted Gtfs from $S$. mutans establishes a co-aggregation between these two organisms, binding with high affinity [61, 62]. The increased ECM biovolume within the dual-species biofilm actively contributes to the pathogenicity of disease, with increased levels of infection and carious lesions observed in vivo [60].

Another molecule worthy of consideration within the context of this interaction is the quorum sensing compound farnesol. This molecule is a key regulator of $C$. albicans biofilm formation [63], and has also been shown to augment antimicrobial therapy and decrease bacterial biofilm formation $[64,65]$. These effects are also observed with $S$. mutans, with high concentrations of the compound inhibiting biofilm formation [66, 67]. Yet, interestingly, when at lower concentrations $(25-50 \mu \mathrm{M})$ that are representative within these dualspecies biofilms, then it can stimulate $S$. mutans microcolony development and enhance biofilm formation [67]. It is therefore thought that this is a key maintenance molecule with regard to regulating microbial fitness and biofilm formation in oral plaque [68]. If indeed candidal yeasts are important physical and metabolic members of cariogenic microbiomes, then this may explain why $S$. mutans centric therapeutic approaches have failed. Taking a holistic microbiological view of this slimy caries environment may lead to combined bacterial and fungal therapeutic approaches.

\section{Angular Cheilitis: Partners in Crime or Peer Pressure?}

Angular cheilitis is a disease characterised by inflammation and crusting of one or more commonly both corners of the mouth [69]. It is a condition of a multifaceted aetiology, including poorly fitted dental appliances, minor trauma, and allergens that account for between 0.7 and $3.8 \%$ of oral mucosal lesions in the adult population [70]. Despite being recognised as a natural inhabitant of the oral microbiome, the role for Staphylococcus aureus in oral disease is underappreciated, though it is commonly isolated in angular cheilitis and associated mucositis (Fig. 1c). Whether it is simply an innocent bystander or actively contributes to pathogenesis is understudied, yet a growing body of evidence yields to the latter [71-74]. A retrospective 10-year analysis by McCormack and co-workers (2015) examined clinical data based on the isolation of $S$. aureus from the oral cavity. Interestingly, the two most common isolation sites were candidal infection and angular cheilitis, both suggestive of a polymicrobial infection with C. albicans [72]. Furthermore, these same two organisms have been co-isolated from the oral cavity, periodontal pockets, and from denture stomatitis [75, 76]. Given this frequent association, several investigations have begun to elucidate the consequences of these interactions with regard to pathogenicity and therapeutic implications. Using a proteomic approach, Peters and colleagues (2010) identified a number of upregulated proteins involved in stress response and metabolism that confers recalcitrance to host defence strategies [77]. Furthermore, a metabolomic-based analysis of the biofilm secretome of these dual-species biofilms identified increased levels of sugar phosphates in comparison to both single-species biofilms, collectively highlighting the complex nature of this relationship [78]. Perhaps the best studied interaction is the attachment of the two microbes. One such phenomena is "microbial hitchhiking," where intricate studies by Schlecht and coworkers (2015) identified the ability of S. aureus upon binding with fungal hyphae to facilitate its own invasion of host tissues [55]. This mechanism, which was dependent on the fungal adhesin $A L S 3$, resulted in recovery of the bacteria from kidney tissue, whereas no recovery was observed in single-species infection. This mechanism is likely responsible for the increased pathogenicity of co-infection observed in vivo [79, 80]. Synergised recalcitrance to antimicrobials has also been observed in several studies $[80,81,82 \bullet \cdot]$. Pioneer studies from Harriot and Noverr (2009) identified a biofilm-mediated resistance against vancomycin within the dual-species biofilm [81]. More recently, the precise mechanism of this resistance has been elucidated, with a suggestive "barrier mechanism," whereby $S$. aureus coats itself in secreted C. albicans matrix 
molecules to impede drug penetration within the biofilm [82••]. Reciprocal resistance has also been observed against miconazole, a dual-active antifungal routinely used in angular cheilitis infections [80].

Given the multifaceted nature of this relationship and their frequent co-isolation from a variety of host niches, then their co-operative role within pathogenicity and disease severity should not go unrecognised. This relationship certainly appears to benefit $S$. aureus, and whether it coerces $C$. albicans by peer pressure to contribute to its success is debatable. We propose that $S$. aureus uses $C$. albicans as a physical scaffold, forming biofilms upon the 3-D hyphal biofilm network, an interaction we term mycofilms [80]. To date, it remains unclear how Candida benefits from the relationship, or whether it is just an unwitting accomplice.

\section{Denture Stomatitis: Mixing in a Rough Neighbourhood}

As the elderly population expands to a predicted 2 billion by 2050 , the number of denture wearers will coincidently rise. Currently, around $20 \%$ of the UK population wear removable dentures of some form, with $70 \%$ of UK adults older than 75 years old wearing dentures [83], with many of these individuals suffering from denture stomatitis (DS), an inflammation of the palate [84]. Poor oral hygiene is frequently observed within this patient group and several factors can impact the onset of DS such as salivary flow, denture cleanliness, age of denture, smoking, and diet [85]. Soft tissue inflammation below or above the denture, as a result of persistent exposure to microorganisms, is characteristic of DS [86]. Microbes frequently adhere to the denture surface and a biofilm quickly develops which can contain numerous species of bacteria and fungi. This is aided by the varied topographical landscape that promotes microbial retention within cracks and crevices of acrylic substrates [83]. Denture plaque microbiome studies by our group have identified a variety of oral pathogens, including cariogenic bacteria, such as the Lactobacillus species that were positively correlated with high levels of Candida [22•] (Fig. 1d).

Discovery of C. albicans and Lactobacillus species in denture plaques was unexpected, as these bacteria have previously displayed antagonism with $C$. albicans at other mucosal sites [87]. The interactions and mechanisms employed by $C$. albicans and Lactobacilli remain somewhat enigmatic. Lactobacilli species have demonstrated the ability to inhibit C. albicans growth via the release of hydrogen peroxide and fatty acids [88]. Previous to this, in an ex vivo experiment, $L$. rhamnosus and $L$. reuteri altered host responses by eliciting an increased inflammatory cytokine response in a C. albicans coinfection model [89]. Hypothetically, a pro-inflammatory response could exacerbate the inflammation of DS whilst ultimately assisting in the clearance of $C$. albicans. Lactobacilli supernatants have been shown to considerably reduce the ability of $C$. albicans to form biofilms [90]. However, the supernatants were unable to significantly reduce the viability of mature biofilms compared to bacterial cell suspensions. It is likely that production of excreted metabolites such as hydrogen peroxide and short-chain fatty acids may interfere with initial adhesion, but direct bacterial-fungal interactions occur to disperse mature $C$. albicans biofilms. Patients with more severe DS are colonised with greater numbers of $C$. albicans and Lactobacilli, indicating the possibility that these organisms can detect changes in their environment and alter their behaviours appropriately to effectively colonise the oral cavity [91].

Although Lactobacillus species are the most commonly isolated bacteria from DS biofilms, other Candida species, namely C. glabrata, have also been detected [92]. Coinfection with $C$. glabrata results in upregulation of key virulence genes (ALS3 and HWPI) in C. albicans [93]. This increased virulence, in return, complements the ability of $C$. glabrata to invade epithelial tissue [94]. Authors hypothesised that during penetration of tissues by $C$. albicans, C. glabrata is transported into host cells via forming aggregates on the hyphae, as has been shown with various bacteria.

As studies get closer to understanding the mechanisms of interactions within dual-species biofilms, this will pave the way to elucidate how interactions within multispecies denture plaque contribute to disease processes. Indeed, it has been shown in vitro that multispecies interkingdom interactions have been shown to synergise one another, with hyphae induced by Streptococcus oralis, and the overall biovolume of denture biofilms is further enhanced with accompanying Actinomyces oris [95]. Understanding the behaviours of multi-species biofilms in vivo will prove more useful in the management of DS, where rough surface topography plays an additional physical role in supporting detrimental interactions. Though, this can be mitigated by physically altering denture surfaces to prevent candida adhesion [96].

\section{Endodontic Infections: Sinister Encounters in the Dark}

Apical periodontitis is a pathological condition that arises from microbial biofilm infection of the intricate anatomy of the root canal system [97, 98]. It is a common condition in primary endodontic infections, and even more so in those that have been previously root canal treated. Significantly, it is a substantial cause of dental morbidity worldwide. Under normal circumstances, the root canal is a sterile environment and any microorganism that invades this space is regarded as a potential cause of disease. Infection of the pulp can range from easy-to-treat infections such as pulpitis to apical periodontitis [99]. Root canal infections are typically of biofilm aetiology, and the causative microorganisms of endodontitis are also found as commensal organisms in the oral cavity. Several 
factors can lead to the onset of endodontic infections such as diet and direct trauma. These can create a gateway to the root canal that oral microorganisms can exploit. Previous studies have shown that endodontic infections are more complex than originally thought. Using NGS techniques, bacteria, fungi, and viruses have been detected within infected root canals [100]. Fungi have been isolated from up to $55 \%$ of root canal infections with $C$. albicans being isolated with the highest frequency [101]. During a 2-year study in a German hospital, patients colonised with C. albicans were found to be two times more likely to be colonised by $E$. faecalis [102]. The ability of $C$. albicans to function in both monomicrobial and polymicrobial communities suggests that it could play a role in the pathogenesis of endodontic infections (Fig. 1e).

E. faecalis, a Gram-positive bacterium, is one of the most commonly isolated bacteria from infected root canals [103]. It has been presented in a recent study that fungi and bacteria can exist within infected root canals in a polymicrobial community [104]. Based on existing knowledge of polymicrobial biofilm communities, these findings could complicate treatment regimens and provide a possible explanation for recurrent root canal infections. Mechanistically, E. faecalis integrates into Candida biofilms and reduces the overall biomass [105], and also been shown to negatively affect $C$. albicans hyphal formation [106]. The protein responsible was identified as the bacteriocin $\mathrm{EntV}$; this secreted protein demonstrated antihyphal and antivirulence properties without antagonising fungal growth [107•]. Co-infection of these organisms has been shown to attenuate $C$. albicans virulence in vivo, particularly with an initial administration of $E$. faecalis $[108,109]$. Interestingly, this effect was also mimicked in a murine oral candidiasis model, whereby initial administration of heatkilled bacteria was shown to have a protective antifungal effect [110]. Together, these studies highlight a potential immunological priming of the host response to withstand fungal infection. In contrast, the $C$. albicans membrane protein Msb2 is able to bind and inactivate host defence proteins and antibiotics, such as daptomycin [111, 112]. Production of Msb2 could subsequently provide the same protection to E. faecalis, leading to long-term colonisation of the root canal. It has also been shown that dual-species biofilms of these two organisms upregulate expression of the $C$. albicans transcriptional regulator WOR1, to which controls the phenotypic switch from the white to opaque cell type, that has been shown to be less susceptible to the innate immune system $[113,114]$. C. albicans has also demonstrated the ability to promote the growth of E. faecalis in the gastrointestinal tract $[115,116]$. These same interactions could likely occur in the root canal, encouraging bacterial growth and preventing resolution of endodontic infection.

\section{Conclusions}

We have highlighted how some key oral diseases are influenced by fungi, which undoubtedly play an important accessory role to a variety of bacterial pathogens. Within the myriad of different microbial interactions that occurs in the oral microbiome, then synergistic and antagonistic dynamic interactions constantly occur, with the most dominant manifesting themselves in disease outcomes. Fungi, and in particular $C$. albicans, can physically, metabolically, and through the release of soluble molecules play an important participatory role in the oral diseases outlined above. It would be naive to think of it simply as an innocent bystander — "guilt by association"; though until it is taken seriously as a keystone oral pathogen/ commensal, then we cannot label it as an accomplice either.

\section{Compliance with Ethical Standards}

Conflict of Interest Christopher Delaney, Ryan Kean, Bryn Short, Maria Tumelty, William McLean, Christopher J. Nile, and Gordon Ramage declare that they have no conflict of interest.

Human and Animal Rights and Informed Consent This article does not contain any studies with human or animal subjects performed by any of the authors.

Open Access This article is distributed under the terms of the Creative Commons Attribution 4.0 International License (http:// creativecommons.org/licenses/by/4.0/), which permits unrestricted use, distribution, and reproduction in any medium, provided you give appropriate credit to the original author(s) and the source, provide a link to the Creative Commons license, and indicate if changes were made.

\section{References}

Papers of particular interest, published recently, have been highlighted as:

- Of importance

• Of major Importance

1. Marsh PD, Zaura E. Dental biofilm: ecological interactions in health and disease. J Clin Periodontol. 2017;44(Suppl 18):S1222. https://doi.org/10.1111/jepe. 12679.

2.•Zaura E, Brandt BW, Prodan A, Teixeira de Mattos MJ, Imangaliyev S, Kool J, et al. On the ecosystemic network of saliva in healthy young adults. ISME J. 2017;11(5):1218-31. https://doi. org/10.1038/ismej.2016.199. A study which highlights the potential of specialised oral ecotypes in prospectively driving a disease state within the oral cavity in otherwise healthy individuals. It also highlights how groups have ecotypes suggestive of dysbiosis, and some with stable ecotypes.

3. Janus MM, Willems HM, Krom BP. Candida albicans in multispecies oral communities; a keystone commensal? Adv Exp Med Biol. 2016;931:13-20. https://doi.org/10.1007/5584_2016_5.

4. Xu X, He J, Xue J, Wang Y, Li K, Zhang K, et al. Oral cavity contains distinct niches with dynamic microbial communities. 
Environ Microbiol. 2015;17(3):699-710. https://doi.org/10.1111/ 1462-2920.12502.

5. Vieira Colombo AP, Magalhaes CB, Hartenbach FA, Martins do Souto R, Maciel da Silva-Boghossian C. Periodontal-diseaseassociated biofilm: A reservoir for pathogens of medical importance. Microb Pathog. 2016;94:27-34. https://doi.org/10.1016/j. micpath.2015.09.009.

6. Shibli JA, Melo L, Ferrari DS, Figueiredo LC, Faveri M, Feres M. Composition of supra- and subgingival biofilm of subjects with healthy and diseased implants. Clin Oral Implants Res. 2008;19(10):975-82. https://doi.org/10.1111/j.1600-0501.2008. 01566.x.

7. Diaz PI, Xie Z, Sobue T, Thompson A, Biyikoglu B, Ricker A, et al. Synergistic interaction between Candida albicans and commensal oral streptococci in a novel in vitro mucosal model. Infect Immun. 2012;80(2):620-32. https://doi.org/10.1128/IAI. 05896-11.

8. Hirschfeld J, White PC, Milward MR, Cooper PR, Chapple ILC. Modulation of Neutrophil Extracellular Trap and Reactive Oxygen Species Release by Periodontal Bacteria. Infect Immun. 2017;85(12). doi:https://doi.org/10.1128/IAI.00297-17.

9. Ramage G, Lappin DF, Millhouse E, Malcolm J, Jose A, Yang J, et al. The epithelial cell response to health and disease associated oral biofilm models. J Periodontal Res. 2017;52(3):325-33. https:// doi.org/10.1111/jre.12395.

10. Millhouse E, Jose A, Sherry L, Lappin DF, Patel N, Middleton $\mathrm{AM}$, et al. Development of an in vitro periodontal biofilm model for assessing antimicrobial and host modulatory effects of bioactive molecules. BMC Oral Health. 2014;14:80. https://doi.org/10. 1186/1472-6831-14-80.

11. Peters BA, Wu J, Hayes RB, Ahn J. The oral fungal mycobiome: characteristics and relation to periodontitis in a pilot study. BMC Microbiol. 2017;17(1):157. https://doi.org/10.1186/s12866-0171064-9.

12. Mukherjee PK, Wang H, Retuerto M, Zhang H, Burkey B, Ghannoum MA, et al. Bacteriome and mycobiome associations in oral tongue cancer. Oncotarget. 2017;8(57):97273-89. https:// doi.org/10.18632/oncotarget.21921.

13. Bamford CV, d'Mello A, Nobbs AH, Dutton LC, Vickerman MM, Jenkinson HF. Streptococcus gordonii modulates Candida albicans biofilm formation through intergeneric communication. Infect Immun. 2009;77(9):3696-704. https://doi.org/10.1128/IAI. 00438-09.

14. Boisvert H, Duncan MJ. Clathrin-dependent entry of a gingipain adhesin peptide and Porphyromonas gingivalis into host cells. Cell Microbiol. 2008;10(12):2538-52. https://doi.org/10.1111/j. 1462-5822.2008.01228.x.

15. Persoon IF, Buijs MJ, Ozok AR, Crielaard W, Krom BP, Zaura E, et al. The mycobiome of root canal infections is correlated to the bacteriome. Clin Oral Investig. 2017;21(5):1871-81. https://doi. org/10.1007/s00784-016-1980-3. A microbiome study which demonstrates the potential of joint bacteriome and mycobiome studies in the oral cavity. Additionally highlights the current limitations of ITS sequencing.

16. Ghannoum MA, Jurevic RJ, Mukherjee PK, Cui F, Sikaroodi M, Naqvi A, et al. Characterization of the oral fungal microbiome (mycobiome) in healthy individuals. PLoS Pathog. 2010;6(1): e1000713. https://doi.org/10.1371/journal.ppat.1000713.

17. Human Microbiome Project C. Structure, function and diversity of the healthy human microbiome. Nature. 2012;486(7402):207-14. https://doi.org/10.1038/nature11234.

18. Dewhirst FE, Chen T, Izard J, Paster BJ, Tanner AC, Yu WH, et al. The human oral microbiome. J Bacteriol. 2010;192(19):5002-17. https://doi.org/10.1128/JB.00542-10.

19. Chen C, Hemme C, Beleno J, Shi ZJ, Ning D, Qin Y, et al. Oral microbiota of periodontal health and disease and their changes after nonsurgical periodontal therapy. ISME J. 2018;12:1210-24. https://doi.org/10.1038/s41396-017-0037-1.

20. Chakravorty S, Helb D, Burday M, Connell N, Alland D. A detailed analysis of $16 \mathrm{~S}$ ribosomal RNA gene segments for the diagnosis of pathogenic bacteria. J Microbiol Methods. 2007;69(2): 330-9. https://doi.org/10.1016/j.mimet.2007.02.005.

21. Rocas IN, Alves FR, Rachid CT, Lima KC, Assuncao IV, Gomes $\mathrm{PN}$, et al. Microbiome of deep dentinal caries lesions in teeth with symptomatic irreversible pulpitis. PLoS One. 2016;11(5): e0154653. https://doi.org/10.1371/journal.pone.0154653.

22. O'Donnell LE, Robertson D, Nile CJ, Cross LJ, Riggio M, Sherriff A, et al. The Oral Microbiome of Denture Wearers Is Influenced by Levels of Natural Dentition. PLOS ONE. 2015;10(9):e0137717. https://doi.org/10.1371/journal.pone. 0137717. A microbiome study which shows a correlation of Candida spp with increased levels of Lactobaccilus spp. An interesting finding as the literature usually presents and antagonistic relationship between these two species.

23. Abusleme L, Dupuy AK, Dutzan N, Silva N, Burleson JA, Strausbaugh LD, et al. The subgingival microbiome in health and periodontitis and its relationship with community biomass and inflammation. ISME J. 2013;7(5):1016-25. https://doi.org/ 10.1038/ismej.2012.174.

24. Sousa V, Nibali L, Spratt D, Dopico J, Mardas N, Petrie A, et al. Peri-implant and periodontal microbiome diversity in aggressive periodontitis patients: a pilot study. Clin Oral Implants Res. 2017;28(5):558-70. https://doi.org/10.1111/clr.12834.

25. Rocas IN, Siqueira JF Jr, Santos KR, Coelho AM. "red complex" (Bacteroides forsythus, Porphyromonas gingivalis, and Treponema denticola) in endodontic infections: a molecular approach. Oral Surg Oral Med Oral Pathol Oral Radiol Endod. 2001;91(4):468-71. https://doi.org/10.1067/moe.2001.114379.

26. Griffen AL, Beall CJ, Campbell JH, Firestone ND, Kumar PS, Yang ZK, et al. Distinct and complex bacterial profiles in human periodontitis and health revealed by $16 \mathrm{~S}$ pyrosequencing. ISME J. 2012;6(6):1176-85. https://doi.org/10.1038/ismej.2011.191.

27. Dupuy AK, David MS, Li L, Heider TN, Peterson JD, Montano EA, et al. Redefining the human oral mycobiome with improved practices in amplicon-based taxonomy: discovery of Malassezia as a prominent commensal. PLoS One. 2014;9(3):e90899. https:// doi.org/10.1371/journal.pone.0090899.

28. Page RC, Engel LD, Narayanan AS, Clagett JA. Chronic inflammatory gingival and periodontal disease. JAMA. 1978;240(6): 545-50.

29. Eke PI, Dye BA, Wei L, Slade GD, Thornton-Evans GO, Borgnakke WS, et al. Update on prevalence of periodontitis in adults in the United States: NHANES 2009 to 2012. J Periodontol. 2015;86(5):611-22. https://doi.org/10.1902/jop. 2015.140520.

30. Hajishengallis G, Darveau RP, Curtis MA. The keystone-pathogen hypothesis. Nat Rev Microbiol. 2012;10(10):717-25. https://doi. org/10.1038/nrmicro2873.

31. Megson ZA, Koerdt A, Schuster H, Ludwig R, Janesch B, Frey A, et al. Characterization of an alpha-1-fucosidase from the periodontal pathogen Tannerella forsythia. Virulence. 2015;6(3):282-92. https://doi.org/10.1080/21505594.2015.1010982.

32. Settem RP, El-Hassan AT, Honma K, Stafford GP, Sharma A. Fusobacterium nucleatum and Tannerella forsythia induce synergistic alveolar bone loss in a mouse periodontitis model. Infect Immun. 2012;80(7):2436-43. https://doi.org/10.1128/IAI.0627611.

33. Canabarro A, Valle C, Farias MR, Santos FB, Lazera M, Wanke B. Association of subgingival colonization of Candida albicans and other yeasts with severity of chronic periodontitis. J Periodontal Res. 2013;48(4):428-32. https://doi.org/10.1111/jre.12022. 
34. Al Mubarak S, Robert AA, Baskaradoss JK, Al-Zoman K, Al Sohail A, Alsuwyed A, et al. The prevalence of oral Candida infections in periodontitis patients with type 2 diabetes mellitus. J Infect Public Health. 2013;6(4):296-301. https://doi.org/10. 1016/j.jiph.2012.12.007.

35. Lambooij JM, Hoogenkamp MA, Brandt BW, Janus MM, Krom BP. Fungal mitochondrial oxygen consumption induces the growth of strict anaerobic bacteria. Fungal Genet Biol. 2017;109:1-6. https://doi.org/10.1016/j.fgb.2017.10.001.

36. Nair RG, Anil S, Samaranayake LP. The effect of oral bacteria on Candida albicans germ-tube formation. APMIS. 2001;109(2): 147-54.

37. Bor B, Cen L, Agnello M, Shi W, He X. Morphological and physiological changes induced by contact-dependent interaction between Candida albicans and Fusobacterium nucleatum. Sci Rep. 2016;6:27956. https://doi.org/10.1038/srep27956.

38. Cavalcanti YW, Wilson M, Lewis M, Del-Bel-Cury AA, da Silva WJ, Williams DW. Modulation of Candida albicans virulence by bacterial biofilms on titanium surfaces. Biofouling. 2016;32(2): 123-34. https://doi.org/10.1080/08927014.2015.1125472.

39. Thein ZM, Samaranayake YH, Samaranayake LP. Effect of oral bacteria on growth and survival of Candida albicans biofilms. Arch Oral Biol. 2006;51(8):672-80. https://doi.org/10.1016/j. archoralbio.2006.02.005.

40. Sztukowska MN, Dutton LC, Delaney C, Ramsdale M, Ramage G, Jenkinson HF, et al. Community Development between Porphyromonas gingivalis and Candida albicans Mediated by InlJ and Als3. mBio. 2018; https://doi.org/10.1128/mBio.0020218.

41. Hajishengallis G, Lamont RJ. Dancing with the stars: how choreographed bacterial interactions dictate Nososymbiocity and give rise to keystone pathogens, accessory pathogens, and Pathobionts. Trends Microbiol. 2016;24(6):477-89. https://doi. org/10.1016/j.tim.2016.02.010.

42. Tamai R, Sugamata M, Kiyoura Y. Candida albicans enhances invasion of human gingival epithelial cells and gingival fibroblasts by Porphyromonas gingivalis. Microb Pathog. 2011;51(4):250-4. https://doi.org/10.1016/j.micpath.2011.06.009.

43. Wu T, Cen L, Kaplan C, Zhou X, Lux R, Shi W, et al. Cellular components mediating Coadherence of Candida albicans and Fusobacterium nucleatum. J Dent Res. 2015;94(10):1432-8. https://doi.org/10.1177/0022034515593706.

44. Brusca MI, Rosa A, Albaina O, Moragues MD, Verdugo F, Ponton J. The impact of oral contraceptives on women's periodontal health and the subgingival occurrence of aggressive periodontopathogens and Candida species. J Periodontol. 2010;81(7):1010-8. https://doi.org/10.1902/jop.2010.090575.

45. Bachtiar EW, Bachtiar BM, Jarosz LM, Amir LR, Sunarto H, Ganin H, et al. AI-2 of Aggregatibacter actinomycetemcomitans inhibits Candida albicans biofilm formation. Front Cell Infect Microbiol. 2014;4:94. https://doi.org/10.3389/fcimb.2014.00094.

46. Vos T, Flaxman AD, Naghavi M, Lozano R, Michaud C, Ezzati $\mathrm{M}$, et al. Years lived with disability (YLDs) for 1160 sequelae of 289 diseases and injuries 1990-2010: a systematic analysis for the global burden of disease study 2010. Lancet. 2012;380(9859): 2163-96. https://doi.org/10.1016/S0140-6736(12)61729-2.

47. Islam B, Khan SN, Khan AU. Dental caries: from infection to prevention. Med Sci Monit. 2007;13(11):RA196-203.

48. Pitts NB, Zero DT, Marsh PD, Ekstrand K, Weintraub JA, RamosGomez F, et al. Dental caries. Nat Rev Dis Primers. 2017;3:17030. https://doi.org/10.1038/nrdp.2017.30.

49. Struzycka I. The oral microbiome in dental caries. Pol J Microbiol. 2014;63(2):127-35.

50. Philip N, Suneja B, Walsh L. Beyond Streptococcus mutans: clinical implications of the evolving dental caries aetiological paradigms and its associated microbiome. Br Dent $\mathrm{J}$. 2018;224(4):219-25. https://doi.org/10.1038/sj.bdj.2018.81.

51. de Carvalho FG, Silva DS, Hebling J, Spolidorio LC, Spolidorio DM. Presence of mutans streptococci and Candida spp. in dental plaque/dentine of carious teeth and early childhood caries. Arch Oral Biol. 2006;51(11):1024-8. https://doi.org/10.1016/j. archoralbio.2006.06.001.

52. Raja M, Hannan A, Ali K. Association of oral candidal carriage with dental caries in children. Caries Res. 2010;44(3):272-6. https://doi.org/10.1159/000314675.

53. Xiao J, Huang X, Alkhers N, Alzamil H, Alzoubi S, Wu TT, et al. Candida albicans and Early Childhood Caries: A Systematic Review and Meta-Analysis. Caries Res. 2018;52(1-2):102-12. https://doi.org/10.1159/000481833. A systematic review which highlights the finding that there is a marked increase in incidence of caries in children who are colonised with $C$. albicans.

54. Koo H, Bowen WH. Candida albicans and Streptococcus mutans: a potential synergistic alliance to cause virulent tooth decay in children. Future Microbiol. 2014;9(12):1295-7. https://doi.org/ 10.2217/fmb.14.92.

55. Schlecht LM, Peters BM, Krom BP, Freiberg JA, Hansch GM, Filler SG, et al. Systemic Staphylococcus aureus infection mediated by Candida albicans hyphal invasion of mucosal tissue. Microbiology. 2015;161(Pt 1):168-81. https://doi.org/10.1099/ mic.0.083485-0.

56. Peters BM, Ovchinnikova ES, Krom BP, Schlecht LM, Zhou H, Hoyer LL, et al. Staphylococcus aureus adherence to Candida albicans hyphae is mediated by the hyphal adhesin Als3p. Microbiology. 2012;158(Pt 12):2975-86. https://doi.org/10. 1099/mic.0.062109-0.

57. Pidwill GR, Rego S, Jenkinson HF, Lamont RJ, Nobbs AH. Coassociation between group B Streptococcus and Candida albicans promotes interactions with vaginal epithelium. Infect Immun. 2018;86:e00669-17. https://doi.org/10.1128/IAI.00669-17.

58. Silverman RJ, Nobbs AH, Vickerman MM, Barbour ME, Jenkinson HF. Interaction of Candida albicans cell wall Als3 protein with Streptococcus gordonii $\mathrm{SspB}$ adhesin promotes development of mixed-species communities. Infect Immun. 2010;78(11):4644-52. https://doi.org/10.1128/IAI.00685-10.

59. Hwang G, Liu Y, Kim D, Li Y, Krysan DJ, Koo H. Candida albicans mannans mediate Streptococcus mutans exoenzyme GtfB binding to modulate cross-kingdom biofilm development in vivo. PLoS Pathog. 2017;13(6):e1006407. https://doi.org/10. 1371/journal.ppat.1006407.

60. Falsetta ML, Klein MI, Colonne PM, Scott-Anne K, Gregoire S, Pai CH, et al. Symbiotic relationship between Streptococcus mutans and Candida albicans synergizes virulence of plaque biofilms in vivo. Infect Immun. 2014;82(5):1968-81. https://doi. org/10.1128/IAI.00087-14.

61. Gregoire S, Xiao J, Silva BB, Gonzalez I, Agidi PS, Klein MI, et al. Role of glucosyltransferase B in interactions of Candida albicans with Streptococcus mutans and with an experimental pellicle on hydroxyapatite surfaces. Appl Environ Microbiol. 2011;77(18):6357-67. https://doi.org/10.1128/AEM.05203-11.

62. Hwang G, Marsh G, Gao L, Waugh R, Koo H. Binding force dynamics of Streptococcus mutans-glucosyltransferase B to Candida albicans. J Dent Res. 2015;94(9):1310-7. https://doi. org/10.1177/0022034515592859.

63. Ramage G, Saville SP, Wickes BL, Lopez-Ribot JL. Inhibition of Candida albicans biofilm formation by farnesol, a quorumsensing molecule. Appl Environ Microbiol. 2002;68(11):545963.

64. Jabra-Rizk MA, Meiller TF, James CE, Shirtliff ME. Effect of farnesol on Staphylococcus aureus biofilm formation and 
antimicrobial susceptibility. Antimicrob Agents Chemother. 2006;50(4):1463-9. https://doi.org/10.1128/AAC.50.4.14631469.2006.

65. Unnanuntana A, Bonsignore L, Shirtliff ME, Greenfield EM. The effects of farnesol on Staphylococcus aureus biofilms and osteoblasts. An in vitro study. J Bone Joint Surg Am. 2009;91(11): 2683-92. https://doi.org/10.2106/JBJS.H.01699.

66. Fernandes RA, Monteiro DR, Arias LS, Fernandes GL, Delbem AC, Barbosa DB. Biofilm formation by Candida albicans and Streptococcus mutans in the presence of farnesol: a quantitative evaluation. Biofouling. 2016;32(3):329-38. https://doi.org/10. 1080/08927014.2016.1144053.

67. Kim D, Sengupta A, Niepa TH, Lee BH, Weljie A, Freitas-Blanco VS, et al. Candida albicans stimulates Streptococcus mutans microcolony development via cross-kingdom biofilm-derived metabolites. Sci Rep. 2017;7:41332. https://doi.org/10.1038/ srep41332.

68. Polke M, Leonhardt I, Kurzai O, Jacobsen ID. Farnesol signalling in Candida albicans - more than just communication. Crit Rev Microbiol. 2018;44(2):230-43. https://doi.org/10.1080/ 1040841X.2017.1337711.

69. Macho VMP, Coelho AS, Veloso ESDM, de Andrade DJC. Oral manifestations in pediatric patients with coeliac disease - a review article. Open Dent J. 2017;11:539-45. https://doi.org/10.2174/ 1874210601711010539.

70. Park KK, Brodell RT, Helms SE. Angular cheilitis, part 1: local etiologies. Cutis. 2011;87(6):289-95.

71. Friedlander AH. Oral cavity staphylococci are a potential source of prosthetic joint infection. Clin Infect Dis. 2010;50(12):1682-3; author reply 3. https://doi.org/10.1086/653003.

72. McCormack MG, Smith AJ, Akram AN, Jackson M, Robertson D, Edwards G. Staphylococcus aureus and the oral cavity: an overlooked source of carriage and infection? Am J Infect Control. 2015;43(1):35-7. https://doi.org/10.1016/j.ajic.2014.09. 015 .

73. Smith AJ, Jackson MS, Bagg J. The ecology of Staphylococcus species in the oral cavity. J Med Microbiol. 2001;50(11):940-6. https://doi.org/10.1099/0022-1317-50-11-940.

74. O'Donnell LE, Smith K, Williams C, Nile CJ, Lappin DF, Bradshaw D, et al. Dentures are a reservoir for respiratory pathogens. J Prosthodont. 2016;25(2):99-104. https://doi.org/10.1111/ jopr.12342.

75. Cuesta AI, Jewtuchowicz V, Brusca MI, Nastri ML, Rosa AC. Prevalence of Staphylococcus spp and Candida spp in the oral cavity and periodontal pockets of periodontal disease patients. Acta Odontol Latinoam. 2010;23(1):20-6.

76. Baena-Monroy T, Moreno-Maldonado V, Franco-Martinez F, Aldape-Barrios B, Quindos G, Sanchez-Vargas LO. Candida albicans, Staphylococcus aureus and Streptococcus mutans colonization in patients wearing dental prosthesis. Med Oral Patol Oral Cir Bucal. 2005;10(Suppl 1):E27-39.

77. Peters BM, Jabra-Rizk MA, Scheper MA, Leid JG, Costerton JW, Shirtliff ME. Microbial interactions and differential protein expression in Staphylococcus aureus -Candida albicans dualspecies biofilms. FEMS Immunol Med Microbiol. 2010;59(3): 493-503. https://doi.org/10.1111/j.1574-695X.2010.00710.x.

78. Weidt S, Haggarty J, Kean R, Cojocariu CI, Silcock PJ, Rajendran $\mathrm{R}$, et al. A novel targeted/untargeted GC-Orbitrap metabolomics methodology applied to Candida albicans and Staphylococcus aureus biofilms. Metabolomics. 2016;12(12):189. https://doi.org/ 10.1007/s11306-016-1134-2.

79. Peters BM, Noverr MC. Candida albicans-Staphylococcus aureus polymicrobial peritonitis modulates host innate immunity. Infect Immun. 2013;81(6):2178-89. https://doi.org/10. 1128/IAI.00265-13.
80. Kean R, Rajendran R, Haggarty J, Townsend EM, Short B, Burgess KE, et al. Candida albicans Mycofilms support Staphylococcus aureus colonization and enhances miconazole resistance in dual-species interactions. Front Microbiol. 2017;8:258 https://doi.org/10.3389/fmicb.2017.00258.

81. Harriott MM, Noverr MC. Candida albicans and Staphylococcus aureus form polymicrobial biofilms: effects on antimicrobial resistance. Antimicrob Agents Chemother. 2009;53(9):3914-22. https://doi.org/10.1128/AAC.00657-09.

82.• Kong EF, Tsui C, Kucharikova S, Andes D, Van Dijck P, JabraRizk MA. Commensal Protection of Staphylococcus aureus against Antimicrobials by Candida albicans Biofilm Matrix. MBio. 2016;7(5). doi:https://doi.org/10.1128/mBio.01365-16. This study allucidates a mechanism by which $S$. aureus acheives vancomycin resistance through the coating in $C$. albicans cell matrix constituents.

83. Hannah VE, O'Donnell L, Robertson D, Ramage G. Denture stomatitis: causes, Cures and Prevention. Prim Dent J. 2017;6(4):4651. https://doi.org/10.1308/205016817822230175.

84. Gendreau L, Loewy ZG. Epidemiology and etiology of denture stomatitis. J Prosthodont. 2011;20(4):251-60. https://doi.org/10. 1111/j.1532-849X.2011.00698.x.

85. Martori E, Ayuso-Montero R, Martinez-Gomis J, Viñas M, Peraire M. Risk factors for denture-related oral mucosal lesions in a geriatric population. J Prosthet Dent. 2014;111(4):273-9.

86. O'Donnell LE, Alalwan HKA, Kean R, Calvert G, Nile CJ, Lappin DF, et al. Candida albicans biofilm heterogeneity does not influence denture stomatitis but strongly influences denture cleansing capacity. J Med Microbiol. 2017;66(1):54-60. https:// doi.org/10.1099/jmm.0.000419.

87. Parolin C, Marangoni A, Laghi L, Foschi C, Nahui Palomino RA, Calonghi N, et al. Isolation of vaginal Lactobacilli and characterization of anti-Candida activity. PLoS One. 2015;10(6):e0131220. https://doi.org/10.1371/journal.pone.0131220.

88. Li H, Liu L, Zhang S, Cui W, Lv J. Identification of antifungal compounds produced by Lactobacillus casei AST18. Curr Microbiol. 2012;65(2):156-61. https://doi.org/10.1007/s00284012-0135-2.

89. Martinez RCR, Seney SL, Summers KL, Nomizo A, De Martinis ECP, Reid G. Effect of Lactobacillus rhamnosus GR-1 and Lactobacillus reuteri $\mathrm{RC}-14$ on the ability of Candida albicans to infect cells and induce inflammation. Microbiol Immunol. 2009;53(9):487-95. https://doi.org/10.1111/j.1348-0421.2009. 00154.x.

90. Matsubara VH, Wang Y, Bandara HMHN, Mayer MPA, Samaranayake LP. Probiotic lactobacilli inhibit early stages of Candida albicans biofilm development by reducing their growth, cell adhesion, and filamentation. Appl Microbiol Biotechnol. 2016;100(14):6415-26. https://doi.org/10.1007/s00253-0167527-3.

91. Bilhan H, Sulun T, Erkose G, Kurt H, Erturan Z, Kutay O, et al. The role of Candida albicans hyphae and Lactobacillus in denture-related stomatitis. Clin Oral Investig. 2008;13(4):363-8. https://doi.org/10.1007/s00784-008-0240-6.

92. Coco B, Bagg J, Cross L, Jose A, Cross J, Ramage G. Mixed Candida albicans and Candida glabrata populations associated with the pathogenesis of denture stomatitis. Mol Oral Microbiol. 2008;23(5):377-83.

93. Alves CT, Wei X-Q, Silva S, Azeredo J, Henriques M, Williams DW. Candida albicans promotes invasion and colonisation of Candida glabrata in a reconstituted human vaginal epithelium. $\mathrm{J}$ Infect. 2014;69(4):396-407. https://doi.org/10.1016/j.jinf.2014. 06.002 .

94. Silva S, Henriques M, Hayes A, Oliveira R, Azeredo J, Williams DW. Candida glabrata and Candida albicans co-infection of an in vitro oral epithelium. J Oral Pathol Med. 2011;40(5):421-7. 
95. Cavalcanti IM, Nobbs AH, Ricomini-Filho AP, Jenkinson HF, Del Bel Cury AA. Interkingdom cooperation between Candida albicans, Streptococcus oralis and Actinomyces oris modulates early biofilm development on denture material. Pathog Dis. 2016;74(3). doi:https://doi.org/10.1093/femspd/ftw002.

96. Alalwan H, Nile CJ, Rajendran R, McKerlie R, Reynolds P, Gadegaard N, et al. Nanoimprinting of biomedical polymers reduces candidal physical adhesion. Nanomedicine. 2018;14(3): 1045-9. https://doi.org/10.1016/j.nano.2018.01.011.

97. Kakehashi S, Stanley HR, Fitzgerald RJ. The effects of surgical exposures of dental pulps in germ-free and conventional laboratory rats. Oral Surg Oral Med Oral Pathol. 1965;20:340-9.

98. Moller AJ, Fabricius L, Dahlen G, Ohman AE, Heyden G. Influence on periapical tissues of indigenous oral bacteria and necrotic pulp tissue in monkeys. Scand J Dent Res. 1981;89(6): 475-84.

99. Persoon IF, Özok AR. Definitions and epidemiology of endodontic infections. Current Oral Health Reports. 2017;4(4):278-85. https://doi.org/10.1007/s40496-017-0161-z.

100. Li L, Hsiao WWL, Nandakumar R, Barbuto SM, Mongodin EF, Paster BJ, et al. Analyzing endodontic infections by deep coverage pyrosequencing. J Dent Res. 2010;89(9):980-4. https://doi.org/ 10.1177/0022034510370026.

101. Egan MW, Spratt DA, Ng YL, Lam JM, Moles DR, Gulabivala K. Prevalence of yeasts in saliva and root canals of teeth associated with apical periodontitis. Int Endod J. 2002;35(4):321-9. https:// doi.org/10.1046/j.1365-2591.2002.00478.x.

102. Hermann C, Hermann J, Munzel U, Rüchel R. Bacterial flora accompanying Candida yeasts in clinical specimens. Mycoses. 1999;42(11-12):619-27. https://doi.org/10.1046/j.1439-0507. 1999.00519.x.

103. Tennert C, Fuhrmann M, Wittmer A, Karygianni L, Altenburger MJ, Pelz K, et al. New Bacterial Composition in Primary and Persistent/Secondary Endodontic Infections with Respect to Clinical and Radiographic Findings. J Endod. 2014;40(5):670-7. https://doi.org/10.1016/j.joen.2013.10.005.

104. Persoon IF, Buijs MJ, Özok AR, Crielaard W, Krom BP, Zaura E, et al. The mycobiome of root canal infections is correlated to the bacteriome. Clin Oral Investig. 2017;21(5):1871-81. https://doi. org/10.1007/s00784-016-1980-3.

105. Fox EP, Cowley ES, Nobile CJ, Hartooni N, Newman DK, Johnson AD. Anaerobic Bacteria grow within Candida albicans biofilms and induce biofilm formation in suspension cultures. Curr Biol : CB. 2014;24(20):2411-6. https://doi.org/10.1016/j. cub.2014.08.057.

106. Cruz MR, Graham CE, Gagliano BC, Lorenz MC, Garsin DA. Enterococcus faecalis inhibits hyphal morphogenesis and virulence of Candida albicans. Infect Immun. 2013;81(1):189 200. https://doi.org/10.1128/iai.00914-12.

107. Graham CE, Cruz MR, Garsin DA, Lorenz MC. Enterococcus faecalis bacteriocin EntV inhibits hyphal morphogenesis, biofilm formation, and virulence of Candida albicans. Proceedings of the National Academy of Sciences. 2017;114(17):4507-12. https:// doi.org/10.1073/pnas.1620432114. A study which describes how the $E$. faecalis bacteriocin, EntV, decreases hyphal formation and virulence of $C$. albicans.

108. Cruz MR, Graham CE, Gagliano BC, Lorenz MC, Garsin DA. Enterococcus faecalis inhibits hyphal morphogenesis and virulence of Candida albicans. Infect Immun. 2013;81(1):189-200. https://doi.org/10.1128/IAI.00914-12.

109. Garsin DA, Lorenz MC. Candida albicans and Enterococcus faecalis in the gut: synergy in commensalism? Gut Microbes. 2013;4(5):409-15. https://doi.org/10.4161/gmic.26040.

110. Ishijima SA, Hayama K, Ninomiya K, Iwasa M, Yamazaki M, Abe S. Protection of mice from oral candidiasis by heat-killed enterococcus faecalis, possibly through its direct binding to Candida albicans. Med Mycol J. 2014;55(1):E9-E19.

111. Swidergall M, Filler SG. Oropharyngeal candidiasis: fungal invasion and epithelial cell responses. PLoS Pathog. 2017;13(1): e1006056. https://doi.org/10.1371/journal.ppat.1006056.

112. Swidergall M, Ernst AM, Ernst JF. Candida albicans mucin Msb2 is a broad-range protectant against antimicrobial peptides. Antimicrob Agents Chemother. 2013;57(8):3917-22. https://doi. org/10.1128/AAC.00862-13.

113. Fox EP, Cowley ES, Nobile CJ, Hartooni N, Newman DK, Johnson AD. Anaerobic bacteria grow within Candida albicans biofilms and induce biofilm formation in suspension cultures. Curr Biol. 2014;24(20):2411-6. https://doi.org/10.1016/j.cub. 2014.08.057.

114. Lohse MB, Johnson AD. White-opaque switching in Candida albicans. Curr Opin Microbiol. 2009;12(6):650-4. https://doi. org/10.1016/j.mib.2009.09.010.

115. Mason KL, Erb Downward JR, Falkowski NR, Young VB, Kao JY, Huffnagle GB. Interplay between the gastric bacterial microbiota and Candida albicans during Postantibiotic recolonization and gastritis. Infect Immun. 2012;80(1):150-8. https://doi.org/10. 1128/IAI.05162-11.

116. Mason KL, Erb Downward JR, Mason KD, Falkowski NR, Eaton KA, Kao JY, et al. Candida albicans and bacterial microbiota interactions in the cecum during recolonization following broadSpectrum antibiotic therapy. Infect Immun. 2012;80(10):3371-80. https://doi.org/10.1128/IAI.00449-12. 